\section{Informational Continuity Is Integral for Successful Transition of Adolescents to Adult Care}

\section{To the Editor:}

Recent reports have suggested that in spite of rheumatology-specific research in the area, there remained a need for further research and development of transitional care for adolescents reaching adulthood, as highlighted in an editorial and paper in this journal ${ }^{1,2}$. In the United States, "Six Core Elements of Health Care Transition" have been defined by the federally funded national resource center on transition (Got Transition) ${ }^{3}$. McManus, et al recently reported a study that observed improvements in all 6 transition quality indicators when these elements were addressed in the clinical setting ${ }^{4}$.

Informational continuity is 1 of several continuities recognized as important in transitional care ${ }^{5}$ and is reflected in several of the core elements referred to above ${ }^{3,4}$. Although a medical summary ${ }^{3}$ as described in core element No. 4 was ranked in the top 2 aspects of successful transition by adult physicians ${ }^{6}$, only $16 \%$ of the North American Childhood Arthritis and Rheumatology Research Alliance (CARRA) members reported as having helped with the creation of a medical summary ${ }^{2}$. Coordinated transitional care, however, has been reported to significantly improve with the provision of such information ${ }^{4,7}$.

We recently carried out a retrospective departmental case note review 8 of all transferred patients during the last 5 years from a department that has an established transitional care program ${ }^{9}$.

Two hundred forty-two patients were identified. Of them, 152 were transferred to 35 rheumatologists and 90 were discharged to primary care. Of the patients transferred, the mean age (SD) at diagnosis was 10 years (1-16) and the mean age at transfer was 17 years (16-19). Sixty-four percent were women $(n=97)$ and $26 \%$ were nonwhite $(n=39)$. Sixty-nine percent had juvenile idiopathic arthritis $(n=105)$ and $59 \%$ were receiving a disease-modifying antirheumatic drug (DMARD)/biologic during transfer $(\mathrm{n}=89)$. Thirty-seven percent had a comorbidity $(\mathrm{n}=56)$.

The median (mean, range) duration between the last pediatric and the first adult appointment was 115 days (102, 0-457; Figure 1). Thirteen patients were lost to followup, including 11 with inflammatory disease, 4 with comorbidities, and 3 receiving a DMARD or a biologic.

We defined successful transfer as receipt of a letter from the first adult appointment, which did not occur in $14 \%$ of cases $(n=22)$, and receipt of a letter from the second adult appointment, which did not occur in $57 \%$ of cases $(n=87)$. Seven were currently being transferred and not included.
Referral letter, health summaries, and copy letters were not documented as having been sent to the adult team from the pediatric team in $24 \%$ of cases $(n=36)$ or to patients themselves in 59\% of cases $(n=89)$.

The results highlight the need for improved consistency of practice both within and between pediatric and adult rheumatology teams to ensure equity, quality, and successful outcomes of transitional care. The acknowledgment that transitional care is a team concern and not the role of a single staff member is fundamental to success ${ }^{10}$. The maintenance processes that will ensure informational continuity should be core knowledge for rheumatology training and staff induction programs. All such information should, in turn, be clearly defined in a written and agreed transition policy - a further core element of transition ${ }^{3,4,8}$.

The initial appointment in adult rheumatology for young people previously cared for in a pediatric center is crucial to ensure engagement in adult services and to establish a therapeutic relationship between the young person and their new rheumatology team. Success will be enhanced if significant lapses of care can be avoided and the adult service is adequately informed about the young person prior to the appointment. This is particularly important for young people taking DMARD/biologics, as well as for those with comorbidities.

Until the implementation of universal electronic patient records, the challenges of informational continuity between pediatric and adult rheumatology centers will remain. Such challenges are particularly pertinent to specialties such as rheumatology that transfer patients to multiple adult providers in geographically diverse hospitals (as opposed to a single regional clinic), often with incompatible information technology systems.

Although the responsibility for timely dictation of referral letters and summaries remains with clinical personnel, the collation of the paperwork, confirmation of what is sent and received, and the tracking of young people into adult care could be undertaken by adequately resourced administration staff in both pediatric and adult rheumatology teams. Such informational continuity will benefit patient care as well as much-needed longitudinal rheumatology research into young adulthood.

NEIL CHANCHLANI, BA, MBChB, Foundation Year Two Doctor, Department of Rheumatology; MARIE McGEE, Transition Coordinator, Birmingham Children's Hospital; JANET E. McDONAGH, MD, MBBS, FRCP, Clinical Senior Lecturer in Paedatric and Adolescent Rheumatology, University of Birmingham, Birmingham, UK. Address correspondence to Dr. N. Chanchlani, Department of Rheumatology, Birmingham Children's Hospital, Birmingham B4 6NH, UK. E-mail: nchanchlani@doctors.org.uk

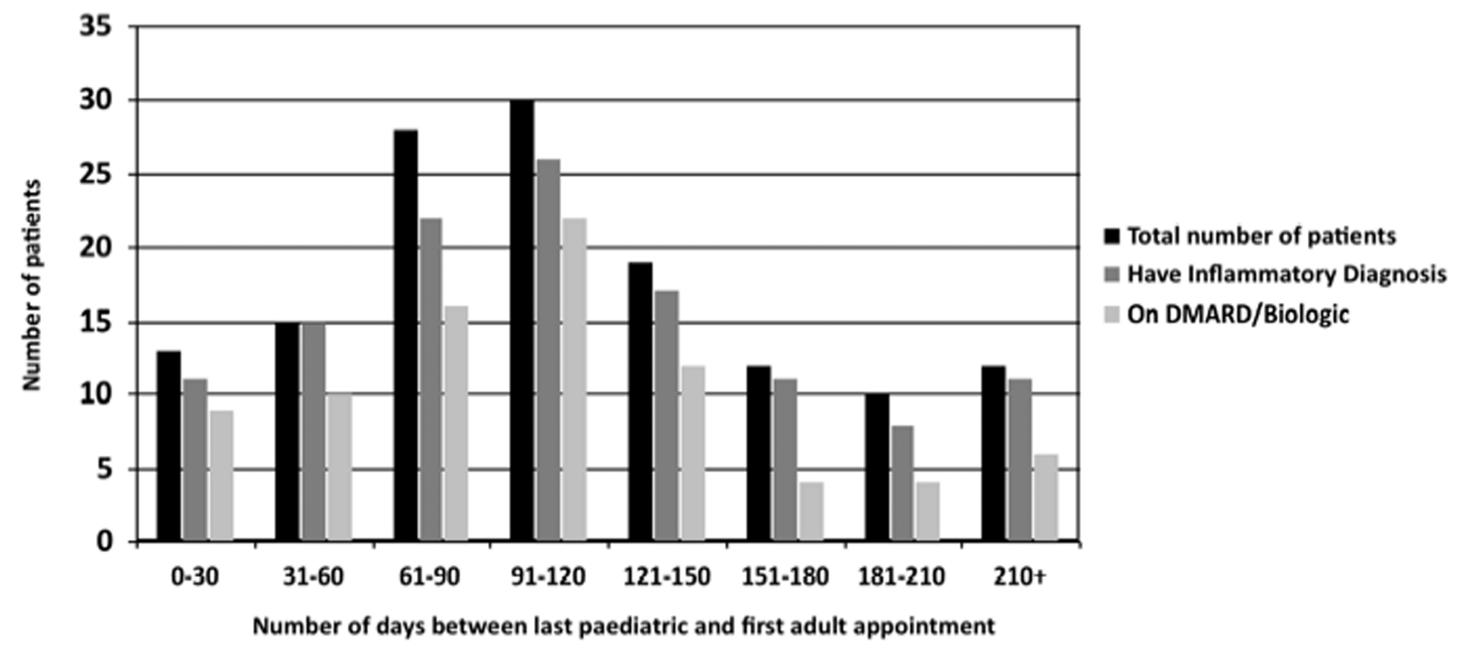

Figure 1. Duration (in days) between last pediatric clinic attendance and first adult clinic attendance. DMARD: disease-modifying antirheumatic drug.

Personal non-commercial use only. The Journal of Rheumatology Copyright @ 2015. All rights reserved. 


\section{REFERENCES}

1. Hersh A. Growing up and moving on - transition of care for patients with childhood-onset rheumatic disease. J Rheumatol 2014; 41:829-31.

2. Chira P, Ronis T, Ardoin S, White P. Transitioning youth with rheumatic conditions: perspectives of pediatric rheumatology providers in the United States and Canada. J Rheumatol 2014;41:768-79.

3. Got Transition. [Internet. Accessed February 4, 2015.] Available from: www.gottransition.org

4. McManus M, White P, Barbour A, Downing B, Hamkins K, Quion $\mathrm{N}$, et al. Pediatric to adult transition: a quality improvement model for primary care. J Adolesc Health 2014;56:73-8.

5. Allen D, Cohen D, Hood K, Robling M, Atwell C, Lane C, et al. Continuity of care in the transition from child to adult diabetes services: a realistic evaluation study. J Health Serv Res Policy 2012;17:140-8.

6. Shaw KL, Southwood TR, McDonagh JE. Developing a programme of transitional care for adolescents with juvenile idiopathic arthritis: results of a postal survey. Rheumatology 2004;43:211-9.
7. Sebastian S, Jenkins H, McCartney S, Ahmad T, Arnott I, Croft N, et al. The requirements and barriers to successful transition of adolescents with inflammatory bowel disease: differing perceptions from a survey of adult and paediatric gastroenterologists. J Crohns Colitis 2012;6:830-44.

8. Chanchlani N, McGee M, McDonagh JE. Arrived safely? Audit of documentation of successful transfer into adult care of young people attending paediatric rheumatology clinics. Rheumatology 2014;53 Suppl 3:iii9.

9. McDonagh JE, Shaw KL, Southwood TR. Growing up and moving on in rheumatology: development and preliminary evaluation of a transitional care programme for a multicentre cohort of adolescents with juvenile idiopathic arthritis. J Child Health Care 2006;10:22-42.

10. Cramm JM, Strating MM, Nieboer AP. The role of team climate in improving the quality of chronic care delivery: a longitudinal study among professionals working with chronically ill adolescents in transitional care programmes. BMJ Open 2014;4:e005369.

J Rheumatol 2015;42:5; doi:10.3899/jrheum.141364 